\title{
A Perspectiva Ecológica: Referências para a Preparação e a Cessação da Estadia em Acolhimento Familiar de Crianças
}

\author{
Ecological Perspective: Guidelines for Planning Child’s Foster Care Placement
}

\author{
Paulo Delgado* \\ Instituto Politécnico do Porto, Porto, Portugal
}

\begin{abstract}
Resumo
A colocação em Acolhimento Familiar e a cessação da estadia constituem transições ecológicas, pelas alterações que acarretam e pelos papéis que atribuem aos seus protagonistas. A preparação destas transições visa não eliminar os obstáculos, uma utopia que o grau de mudança não permite, mas diminui-los, para um nível que facilite o desenvolvimento da criança e a integração na fase seguinte da sua vida. Este artigo revê o trabalho de alguns autores que, no Reino Unido, se têm debruçado sobre a preparação da colocação e da cessação do Acolhimento Familiar. O modelo ecológico é utilizado como quadro teórico orientador daquela medida de protecção e identifica um conjunto de factores que potencializam o sucesso das transições.

Palavras-chave: Perspectiva ecológica, acolhimento familiar, transição ecológica, preparação da colocação, preparação da cessação.
\end{abstract}

\begin{abstract}
The placement in foster care and its ceasing are ecological transitions due to the changes they bring and because of the roles assigned to their protagonists. The preparation of such transitions aims to not diminish the obstacles, a utopia that the degree of change does not allow, but to diminish them to a degree that makes the child integration in his/her next phase of life easier. This article reviews the work of some British authors who have taken a special interest in the preparation and closure of children's foster care. It also intends to legitimize, from a theoretical point of view, the relevance of using the ecological model as a guiding framework of that protective measure and suggests a set of practices which enhance the success of the transitions.

Keywords: Ecological perspective, foster care, ecological transition, foster placement planning, foster placement ending.
\end{abstract}

\section{A Perspectiva Ecológica e o Acolhimento Familiar}

A obra de Bronfenbrenner (1979/1996, 2005) descreve a relação entre o ambiente e o desenvolvimento humano, sublinhando o modo como o espaço ecológico-social em que o indivíduo está inserido influencia o seu percurso, condicionando-o ou potenciando-o, por intermédio das interacções que, ao longo da vida, os indivíduos mantêm com o meio envolvente. Na perspectiva ecológica, ecosocial ou ecosistémica "os sujeitos, longe de serem um produto passivo do ambiente, são agentes dinâmicos do mesmo, edificando realidades" (Caride \& Meira, 1995, p. 146), através da

\footnotetext{
* O artigo apresentado insere-se num projecto de investigação que tem o apoio do Ministério da Ciência, Tecnologia e Ensino Superior português, no âmbito de uma Bolsa de Pós-Doutoramento, atribuída pela FCT - Fundação para a Ciência e a Tecnologia (com a referência SFRH/BPD/20443/2004).

Endereço para correspondência: Escola Superior de Educação, Instituto Politécnico do Porto, Rua Dr. Roberto Frias, 602, Porto, Portugal 4200-465. E-mail pdelgado@ese.ipp.pt
}

interacção com os elementos demográficos, físico-naturais, sociais e culturais de uma comunidade (Meira, 1999).

O espaço ecológico "é concebido como uma série de estruturas encaixadas, uma dentro da outra, como um conjunto de bonecas russas" (Bronfenbrenner, 1979/1996, p. 5), mas que não estão hermeticamente fechadas, umas em relação às outras, das mais pequenas à maior. Ancorada na teoria sistémica, a perspectiva ecológica reconhece a interdependência e a inter-relação entre os diferentes níveis ambientais e os componentes que os compõem, produzindo, no seu conjunto, um meio que é globalmente distinto (pode ser mais ou pode ser menos) da mera soma de cada uma das suas parcelas (Alarcão, 2000; Relvas, 1996). Todavia, apesar de partirem do mesmo tronco comum, são distintas as acepções conceptuais e metodológicas da perspectiva sistémica e ecológica, "sendo este último o que recolhe as considerações do primeiro" (García \& Melían, 1993, p. 80).

Numa apreciação crítica à perspectiva sistémica e ecológica, Payne (2005, p. 157) reconhece-lhe as seguintes vantagens: enfatiza as mudanças ambientais em detrimen- 
to das abordagens psicológicas; concentra-se nos efeitos de uma pessoa sobre a outra mais do que nos pensamentos ou sentimentos internos; alerta para a possibilidade de alcançar a mesma finalidade seguindo caminhos alternativos; é unitária, integrada e holística; e evita explicações lineares ou determinísticas (tipo causa-efeito) do comportamento ou dos fenómenos sociais.

São quatro os círculos que, segundo Bonfrenbrenner (1996), rodeiam ou integram a pessoa no seu núcleo. O microsistema é o primeiro, o mais íntimo e imediato, ou mais conhecido, que envolve o indivíduo desde os primeiros anos de vida, e as interacções que desenvolve em territórios como a casa/família, com os pais e os irmãos, a sala de aula ou o parque infantil. O mesosistema é um sistema composto por microsistemas e será tanto mais poderoso e rico para o desenvolvimento da criança quanto mais diversos e fortes são os vínculos entre os meios, com particular destaque para o que liga a família à escola (Garbarino \& Eckenrode, 1999). O exosistema constitui o terceiro nível ecológico e refere-se à comunidade envolvente em que as famílias se inserem e ao mundo do trabalho (Alberto, 2004). São ambientes mais afastados, nos quais o indivíduo pode nem estar presente, mas cujos acontecimentos influenciam o seu desenvolvimento. $\mathrm{O}$ último nível socioambiental remete para a cultura social, para os valores, as crenças e os modos de agir de uma determinada sociedade, para a forma como ela se organiza, desde o espaço mais privado (microsistema) à esfera nacional.

O desenvolvimento humano resulta da correlação que se estabeleça entre a hereditariedade e o ambiente ecológico e define-se como "o fenómeno de continuidade e mudança nas características biopsicológicas dos seres humanos como indivíduos e como grupos" (Bronfenbrenner, 2005, p. 3). Correlação porque entre o individuo e o ambiente desenvolve-se uma interacção recíproca, isto é, por um lado o meio ambiente exerce a sua influência, por outro o indivíduo penetra no meio em que reside e reestrutura-o, originando um processo de acomodação mútua (Bronfenbrenner, 1979/1996), que não pode ser compreendido à margem das circunstâncias quotidianas e dos contextos em que tem lugar (Caride \& Meira, 1995), porque a criança não cresce no "vácuo" (Daniel, Wassell, \& Gilligan, 1999). A integração ou a inadaptação não existem fora dos contextos sociais e remetem, necessariamente, para ambientes concretos (Garbarino \& Barry, 1999), que a perspectiva ecológica ajuda a compreender.

O modelo ecológico-social de Bronfrenbrenner pode ser utilizado para caracterizar e compreender a colocação familiar, as interacções e conexões entre os diferentes níveis ecológicos que o novo contexto de vida da criança determina. O Acolhimento Familiar é um serviço especializado que proporciona um contexto familiar alternativo, quando o perigo torna a retirada da criança inevitável. Proporciona à criança a possibilidade de continuar a viver com uma família, porém num lar novo e inteiramente desconhecido, na companhia de outros adul- tos e crianças que nunca vira até então, com os seus costumes, as suas regras, os seus valores, os seus afectos, um modo de ser muito provavelmente distinto do padrão a que estava habituada. Noutros casos, passará a viver com os seus avós ou outros parentes, nas suas casas, com pessoas e espaços que poderão ser mais ou menos conhecidos. Em paralelo, deverá decorrer um trabalho junto da família biológica tendo em vista a reunificação familiar, sempre que as dificuldades forem reversíveis (Orte, 1999), uma vez que as "boas práticas parentais não são um dado da natureza, nem dependem apenas dos sentimentos - exigem a aquisição de competências específicas" (Almeida, André, \& Almeida, 1999, p. 143).

Entre as várias definições de Acolhimento Familiar, escolhemos a de Colton e Williams (1997), porque se baseia numa perspectiva comparada da medida, alicerçada no estudo do acolhimento em 21 países, dos cinco continentes do mundo. O Acolhimento Familiar é:

o cuidado prestado na casa dos acolhedores, numa base temporária ou permanente, através da mediação de uma autoridade reconhecida, por acolhedores específicos, que podem ou não ser parentes da criança acolhida (definida de modo diferente em diferentes países), que pode ou não residir oficialmente com eles. (p. 292)

Ser acolhido representa desde logo, ao nível do microsistema, e do ponto de vista da criança, a entrada numa nova casa e a integração num novo espaço familiar, que deve ser, simultaneamente, um ambiente terapêutico para a criança, que promove a mudança para padrões seguros de apego (Cairns, 2002). O nível ecológico de maior proximidade e permanência passa a ser composto pela família dos acolhedores, pela interacção que a criança acolhida estabelece e desenvolve com cada um dos membros da família de acolhimento.

No mesosistema, destaque para a relação que a família de acolhimento passa a desenvolver com a Equipa de Acolhimento e com a família biológica (ou com os anteriores detentores da guarda da criança), bem como destas entre si, compondo este triângulo relacional, mais ou menos cooperativo, a essência interaccional da colocação, com a criança no centro. A perspectiva ecológica propõe um relacionamento inclusivo, em que os protagonistas trabalham em rede para maximizar o apoio social disponível para a criança protegida (Wade, 1999).

No exosistema integram-se as transformações que vão alterando a configuração da família de acolhimento bem como os acontecimentos relevantes que afectam a família biológica e a sua condição social, económica e cultural. Apesar da criança não participar directa ou activamente nestas esferas, a possibilidade de regresso a casa pode ser condicionada ou facilitada pelo decurso desses acontecimentos, deles dependendo eventualmente também, ainda que de um modo indirecto, as suas possibilidades de desenvolvimento. A própria intervenção da Equipa de Acolhimento, a qualidade do acompanhamento e da tomada de decisão está relacionada com as opções 
que, a nível local, forem tomadas pela entidade de enquadramento.

Por fim, ao nível do macrosistema, sublinhem-se os padrões culturais e ideológicos predominantes que representam os valores e as crenças sobre a família e sobre o Acolhimento Familiar. A atribuição de prioridade ao Acolhimento familiar no âmbito das políticas sociais de protecção das crianças em perigo, face às outras medidas de colocação, é um sintoma dos princípios jurídicos e filosóficos vigentes.

Obviamente esta representação não é estática. A qualquer momento podem ocorrer mudanças no ambiente ecológico, em resultado da dinâmica familiar (e aqui inclui-se a família de acolhimento e a família biológica), ou da própria natureza da medida, que pode ser sujeita a modificações (nomeadamente no esquema de contacto com a família biológica, ou na passagem de um acolhimento de curta duração para um acolhimento prolongado) ou até cessar (pelo regresso da criança a casa ou pela passagem para outra medida, como o Acolhimento Residencial). Por outro lado, e à medida que o tempo passa, permanecendo a criança acolhida, experimentará um conjunto de transições no meio ambiente, como a entrada na escola, o desempenho de uma nova actividade desportiva ou cultural ou a mudança dos técnicos da Equipa de Acolhimento que se ocupam do seu processo.

O próprio macrosistema está sujeito a uma contínua reestruturação, podendo suceder, por exemplo, que a política de intervenção socioeducativa passe a privilegiar a colocação familiar das crianças e jovens, em detrimento da sua institucionalização, como sucedeu nas últimas décadas em diversos países europeus.

As transições ecológicas vão ocorrendo ao longo da vida de todos os sujeitos e consistem em mudanças de papel ou ambiente, como a entrada na escola, a mudança de emprego ou de casa, a doença, o casamento e o divórcio, ter um filho ou um irmão. A cada um destes novos papéis associa-se a expectativa do desempenho de um conjunto de comportamentos, que alteram "a maneira pela qual a pessoa é tratada, como ela age, o que ela faz, e inclusive o que ela pensa e sente" (Bronfenbrenner, 1979/ 1996, p. 7).

A colocação em Acolhimento Familiar, e, mais tarde, a sua cessação, constitui um momento de transição de uma enorme extensão e significado, pelas alterações que acarreta e pelos novos papéis que atribui aos seus protagonistas. Constitui também um momento traumático, pelos maus tratos sofridos e que conduziram à colocação e pela retirada, pelo "desenraizamento" que provoca e que revela, amiúde, atrasos no desenvolvimento cognitivo, intelectual, emocional e social da criança. Num território desconhecido, ela vê-se confrontada com novos espaços de identificação, com outros lugares de encontro e de aç̧ão.

Uma vez apresentada a perspectiva sócio-ecológica, este artigo reflecte sobre os procedimentos da fase inicial da colocação familiar, apurados na reflexão conceptual e nos estudos desenvolvidos no Reino Unido, um dos sistemas de protecção onde o Acolhimento Familiar adquiriu maior expressão e desenvolvimento, e prossegue com a caracterização do período de cessação da estadia. Termina com uma reflexão acerca dos factores que condicionam ou facilitam as transições ecológicas que ocorrem no Acolhimento Familiar, de modo a potencializar a integração da criança e o seu pleno desenvolvimento.

A política de colocação de crianças em perigo privilegia, há muitos anos, o Acolhimento Familiar, que chega a atingir os $80 \%$ das colocações em partes do Reino Unido. Em meados do século XX, esta medida já representava $50 \%$ das colocações (Sellick, 2006), tendo ultrapassado desde então a colocação residencial como a primeira escolha para a colocação das crianças em perigo. O reforço da preservação familiar diminuiu, nos últimos 25 anos, o número de crianças a que é aplicada uma medida de colocação, e aumentou, em contrapartida, o grau de dificuldade emocional e comportamental das crianças que são colocadas (Sellick \& Thoburn, 1997).

O acolhimento por famílias com laços de parentesco, apesar de minoritário, tem crescido nos últimos anos, bem como a procura de respostas para a colocação familiar de crianças que manifestam um elevado grau de dificuldade, por se entender que, mesmo nesses casos, o Acolhimento Familiar, necessariamente especializado, é sempre preferível. Entre os principais desafios que o futuro do Acolhimento Familiar apresenta, Sellick (2006) destaca precisamente a necessidade de maximizar o recrutamento e a escolha no momento da colocação bem como criar, financiar e apoiar o acolhimento de longa duração, para as crianças que não podem regressar a casa ou ser adoptadas.

\section{A Perspectiva Ecológica na Preparação da Colocação em Acolhimento Familiar}

A inadaptação não existe fora de ambientes concretos, que a perspectiva ecológica estuda, analisa e interpreta. O mesmo se pode dizer da integração. Quando a criança se encontra numa situação de perigo, e é aconselhável afastá-la do convívio com a sua família ou meio natural de vida, a retirada pode dirigi-la para o Acolhimento $\mathrm{Fa}$ miliar. Ela experimenta então uma transição ecológica radical, uma vez que, no microsistema novo encontra adultos desconhecidos com funções parentais, outros adultos idosos ou crianças, mais novas ou mais velhas, que também provavelmente desconhece, com quem tem de se relacionar de perto e diariamente. Descobre uma casa de família misteriosa, que nunca frequentou, assim como o espaço da rua ou do bairro onde passa a viver, parques infantis, jardins, zonas desportivas ou instalações com fins recreativos ou culturais que talvez nunca tenha utilizado e que passam a fazer parte da sua geografia quotidiana. A que acresce a presença mais assídua e com intromissões até então inexistentes dos técnicos da equipa ou equipas responsáveis pela sua colocação. 
Todas estas mudanças são vividas numa situação de fragilidade emocional, caracterizada pela dor, pelo medo do desconhecido, eventualmente pelo sentimento de culpa e pela saudade dos pais, irmãos, outros familiares e amigos que passa a ver pontualmente, em visitas pré-definidas, com mais ou menos frequência. Muda de "pais", muda de "irmãos", de amigos, de casa e pode mudar de escola, tudo ao mesmo tempo o que origina, em consequência, um mesosistema novo, de acordo com o padrão com que cada um dos espaços referidos se alinha e interage com os restantes.

À chegada, a criança experimenta geralmente um conjunto de sentimentos dolorosos e por vezes contraditórios. O medo do desconhecido, o sentimento de culpa pelo maus tratos sofridos, que se mistura com a lealdade relativamente aos que abandona (Schofield, Beek, Sargent, $\&$ Thoburn, 2000), a dor e o trauma associados à retirada, a perda de identidade, a incerteza relativamente ao futuro, são alguns exemplos de um "estado de alma" fragilizado, que sinaliza a importância da preparação e do acompanhamento da fase inicial da estadia. A criança manifesta, em muitos casos, resistência à aceitação dos acolhedores, e desconfiança face às situações de aprendizagem que o novo contexto lhe propõe, sendo incapaz de "processar as novas informações acerca da realidade, que os seus dedicados acolhedores não são como os adultos que cuidavam dela anteriormente e que talvez a representação mental do adulto cuidador tenha de ser alterada" (Beek \& Schofield, 2004, p. 7). Na dúvida, perante um contexto desconhecido, e com pessoas e propostas surpreendentes, prefere partir do princípio que a querem enganar, ancorando-se na suspeita e na incredulidade, posicionamento que tem tendência a acentuar-se quanto mais idade tiver e mais insatisfatórias tiverem sido as experiências anteriores de acolhimento.

Quando o acolhimento se prolonga no tempo, e a colocação resulta, e isso sucede quando a criança e acolhedores "encaixam" como as peças de um quebra-cabeça, esses sentimentos atenuam-se progressivamente, até desaparecerem e serem substituídos pela segurança, pelo conforto material, pelos laços afectivos que, lentamente, se vão erguendo entre acolhedores e acolhidos e que podem originar um sentimento de filiação e de paternidade (acolhimento familiar de tipo substitutivo). Podem originar também a divergência e um conflito de vontade face aos dois contextos de vida.

Noutros casos, a colocação não é feliz, a comunicação não resulta, o desgaste acumula-se, surgem os conflitos e ocorre a ruptura, num encadeamento que pode inclusivamente ameaçar (ou destruir) o equilíbrio da família acolhedora (Sinclair, Gibbs, \& Wilson, 2004). Recordese que o desenvolvimento psicológico dos pais, ou dos acolhedores que desempenham esse papel, é fortemente influenciada pelo comportamento e desenvolvimento das crianças (Bronfenbrenner, 2005). Também acontece que a estadia seja curta porque é possível garantir o rápido regresso à família e nessas circunstâncias, de maior proximidade e contacto com os pais, o acolhimento tem um menor impacto no desenvolvimento da criança (acolhimento familiar de tipo complementar). Noutras circunstâncias, a estadia decorre normalmente até à idade da adolescência para surgirem então os problemas e as dificuldades na permanência.

São, enfim, muito diversas as situações, e cada uma constitui um caso singular, irrepetível e imprevisível quanto aos seus resultados (Berridge, 1997; Bullock, 1999; Schofield et al., 2000; Sinclair, Wilson, \& Gibbs, 2005). Neste quebra-cabeças complexo e sujeito à mudança, descrito entre outros por Berridge (1999), Neil e Howe (2004) referem duas condições que, não sendo por si só suficientes, podem ajudar a obter resultados positivos: a compatibilidade entre a criança e os acolhedores e conseguir gerir os factores provenientes do espaço exterior que colidem com o acolhimento, "o que inclui o relacionamento com a família biológica mas também a resposta da escola, dos trabalhadores sociais e dos próprios membros da família de acolhimento" (p. 175).

A preparação da colocação reduz os efeitos traumáticos da separação e implica, idealmente, uma selecção e uma escolha. Uma selecção de um grupo de potenciais acolhedores, se existirem opções disponíveis em fila de espera, atendendo às características da criança, à sua etnia, classe, religião e cultura, aos seus antecedentes e aos desafios que coloca, e a outros factores, como o local do acolhimento e a duração do período no qual, previsivelmente, se vai prolongar a estadia (Schofield et al., 2000; Triseliotis, Borland, \& Hill, 2000). Isto sem omitir, obviamente, o perfil e a vontade da família de acolhimento, e ainda as necessidades e a vontade que a criança possa expressar sobre o perfil dos acolhedores.

A escolha aumenta as probabilidades de integração da criança e, por consequência, de estabilidade no acolhimento. Pelo contrario, a falta de preparação, interagindo com outros elementos, é uma das variáveis incluídas nos factores que antecipam o resultado negativo da colocação, referidos por Triseliotis, Sellick e Short (1995).

Os acolhedores devem dispor de informação que lhes permita compreender, na criança em causa, o seu nível de desenvolvimento cognitivo e emocional, a sua saúde e historial clínico, os seus métodos de comunicação, as brincadeiras e as suas actividades preferidas. Devem igualmente saber o que necessita para se sentir segura, a sua experiência e expectativas em relação à vida familiar e à relação parental, o modo como reagiu à separação, os modos como gere os relacionamentos (padrão comportamental e de apego), quem são as pessoas importantes na sua vida e qual o seu grau de compreensão sobre o que vai acontecer no futuro (Romaine, Turley, \& Tuckey, 2007, p. 26). Estes dados são essenciais para tomarem uma decisão sobre o acolhimento (Sinclair et al., 2004).

Pelo exposto, é possível definir um conjunto de requisitos que devem orientar a transição inicial para o acolhimento que se devem estender à criança, porque se é um 
facto que "os acolhedores potenciais querem saber tudo o que é possível sobre a nova criança, também esta quer saber tudo o que for possível sobre a sua nova família" (Daniel et al., 1999, p. 97) e sobre o processo em que está envolvida, nomeadamente sobre as mudanças e as decisões que previsivelmente irão ocorrer.

Bronfenbrenner (1979/1996) afirma que o potencial de integração aumenta se a entrada no novo meio ocorrer na companhia de uma ou mais pessoas com os quais a criança participou em ambientes anteriores, o que, neste caso específico, se aplica aos pais biológicos ou outros familiares da criança, e, de modo mais significativo, aos técnicos dos Serviços Sociais responsáveis pelo caso (por exemplo, o assistente social acompanha a criança a casa da família de acolhimento). Neste grupo podem-se incluir os próprios acolhedores, quando é possível planificar a transição e prever espaços de conhecimento e de convívio com a criança antes de se iniciar a colocação.

Quando as ligações entre os ambientes assentam na confiança mútua e na partilha de objectivos, a fase inicial do acolhimento é mais rápida e a adaptação facilitada. Esta constatação evidencia a influência dos pais biológicos ou dos familiares com quem a criança vivia, quando se opõem e recusam ou aceitam e incentivam a colocação. O tipo e a extensão da comunicação entre a família de acolhimento, a família biológica, a equipa de acolhimento e a criança, quando dispõe da idade e maturidade necessárias, interfere de igual modo na transição, facilitando-a, quando é fluida e pertinente, ou tornando-a mais difícil, quando não funciona, ou funciona deficitariamente, com ambiguidades ou omissões.

O conjunto de dados de que os protagonistas dispõem antes de se iniciar a estadia, ou mesmo os contactos iniciais (quando são possíveis) influenciam a sua decisão, a sua postura, as suas expectativas e a sua reacção face aos obstáculos futuros. Em suma, determinam, em parte, a probabilidade de sucesso da colocação. Os acolhedores que recebem crianças consideravelmente diferentes do tipo que desejavam têm acolhimentos mais difíceis (Sellick, Thoburn, \& Philpot, 2004).

Exceptuando os casos de urgência, a colocação deve ser programada. A programação difere de acordo com a modalidade de acolhimento em causa. Como evidenciaram Schofield et al. (2000), o acolhimento prolongado deve ser preparado com um tempo de aproximação e conhecimento que não se justificará no caso dos acolhimentos familiares de curta duração ou no caso do acolhimento na família extendida, quando a criança conhece e tem uma proximidade afectiva com os parentes que a passam a acolher. O que não significa que não deva ocorrer no último caso, como parece suceder muitas vezes.

A colocação deve ser acompanhada pelo trabalho com a família biológica, nos momentos que a antecedem e durante a estadia (Sellick et al., 2004), o que nos remete para a fase subsequente do acompanhamento do acolhimento. O técnico da Equipa de Acolhimento pode ser um interlocutor privilegiado para a família biológica, com quem os pais sintam à vontade para confessar o desejo de se "reapropriarem" da criança, ou de a abandonarem em definitivo, oscilações particularmente dolorosas para a criança e para os próprios acolhedores. À semelhança do que deve suceder com a criança e com os acolhedores, também a família biológica deve ser informada do processo de protecção em curso, das razões que fundamentam a separação, dos seus deveres e direitos e modos para os exercer.

Após a integração da criança na família de acolhimento, e enquanto decorrer a estadia, impende sobre a Equipa de Acolhimento competente a responsabilidade de suportar, ajudar, promover e avaliar a colocação, até ao momento em que cessa, seja qual for a causa da cessação. A medida não se esgota com a colocação, bem pelo contrário, e combina, no acompanhamento, o apoio com a avaliação (Schofield et al., 2000).

\section{Intervenção Socioeducativa na Cessação do Acolhimento}

Quando o Acolhimento Familiar termina, a criança ou jovem é sujeito a uma nova transição ecológica. Os comentários relativos à preparação da colocação aplicamse, em grande parte, ao momento da cessação, nomeadamente o modo como decorre, a ligação que existia e a ligação que subsiste, no futuro, entre os dois ambientes, a forma como estes comunicavam e passam a comunicar entre si, e o volume de conhecimentos e de experiências que o individuo transporta consigo na mudança e pode utilizar no meio em que se integra. Sinclair, Baker, Wilson e Gibbs (2005) realçam a importância e a complexidade desta passagem, chegando a afirmar que "o calcanhar de Aquiles do sistema reside não no que acontece durante o acolhimento mas no que se lhe segue" (p. 251).

Comecemos pelo modo como se processa a cessação. A colocação pode ser revogada, pode caducar ou pode ainda cessar por ruptura, quando a incompatibilidade entre acolhedores e criança se acentua ao ponto de impedir a vida conjunta ou quando a ocorrência de outras circunstâncias graves determina a retirada imediata da criança. Ou seja, a estadia cessa neste último caso de forma não planeada (Romaine et al., 2007). Das diferentes formas de cessação, esta é a mais traumática, a mais indesejável e a que pode ter consequências gravosas para a futura integração e desenvolvimento da criança e para a própria família de acolhimento. A experiência negativa pode levála a repensar a continuidade no sistema. Por outro lado, coloca um problema "em cima da mesa" que exige uma rápida resposta: qual deve ser o destino da criança, se regressar ao local onde se encontrava anteriormente ou se procurar uma resposta de colocação alternativa. Sinclair et al., (2004) advogam que uma ruptura deve sempre ser seguida de um balanço entre os acolhedores e a Equipa de Acolhimento, sobre o que correu mal e que lições se 
podem tirar para o futuro. Esta reflexão potencia a continuidade dos acolhedores no sistema e permite-lhes gerir a dor ou sofrimento associada à separação.

Sinclair, Wilson et al. (2005) citam um conjunto de estudos para concluir que os factores que mais conduzem à ruptura são a idade mais avançada da criança, os padrões de comportamento problemáticos, certas características e alguma falta de preparação dos acolhedores e a falta de cuidado no matching, particularmente no que diz respeito 'a diferença de idades entre as crianças acolhidas e as crianças da casa. Triseliotis et al. (2000) destacam o impacto negativo do acolhimento na família e a falta de apoio e de resposta dos Serviços Sociais, ao longo do tempo e no período da crise. Schofield et al. (2000) destacam, por sua vez, a importância para o acolhimento da relação entre acolhedores e criança acolhida ser necessariamente calorosa e mutuamente gratificante, sob pena de conduzir a maus resultados, ao desapontamento e, eventualmente, à ruptura.

A revogação sucede por sua vez face a uma nova manifestação de vontade da entidade pública com competência legal neste âmbito, que determina o fim da colocação, conduzindo a criança para um novo Acolhimento Familiar, aplicando-lhe outra medida de colocação ou decidindo o seu regresso a casa, através da reintegração na família biológica. A criança muda de microsistema, passa a viver num ambiente diferente, com outras pessoas, e noutro local. Esta decisão requer uma competência profissional apurada e é das mais difíceis que a Equipa de Acolhimento tem de tomar (Triseliotis et al., 1995).

Sinclair (2005) analisou recentemente um conjunto de 16 projectos de investigação centrados nas crianças acolhidas ou nos acolhedores, publicados ou terminados a partir de 1998. O investigador concluiu que a maioria das crianças não quer regressar a casa e pensa que prolongar o acolhimento é uma boa solução. A vontade de regressar é baixa e para os que regressaram correu muitas vezes mal, com a reincidência dos maus tratos. A insistência na manutenção do regresso gerou como consequências uma menor probabilidade de adopção e, provavelmente, crianças seriamente traumatizadas e abusadas, o que parece aconselhar esquemas alternativos de longa duração.

Finalmente, a caducidade surge quando o acolhimento cessa sem uma nova manifestação de vontade, terminando por razões intrínsecas. É o que sucede quando a criança atinge a maioridade ou o limite etário definido para o Acolhimento familiar. É o que ocorre também quando se transita do acolhimento para a autonomia de vida, e se procura construir a independência, não obstante as dificuldades de alguém se tornar independente aos 18 anos. Legalmente, é-se adulto, mas na prática, depende-se com frequência dos pais e da família, e, em muitos casos, por muitos anos mais. O que leva Maluccio, Ainsworth e Thoburn (2000, p. 88) a proporem, numa abordagem verdadeiramente ecológica, a substituição do conceito de vida independente pelo conceito de vida interdependente, que sublinha a interacção, a influência e a partilha de recursos e actividades numa comunidade, e aponta para a necessidade de uma preparação cuidadosa da transição, ao nível da formação e do apoio disponível.

De acordo com Colton e Williams (2006), os jovens que transitam do acolhimento, se comparados com os jovens que vivem com a sua família, sentem ainda maiores dificuldades na organização de uma vida autónoma. Se não são devidamente apoiados pelo sistema, quando não podem contar com a sua família, acabam por depender do apoio ou da ajuda dos ex-acolhedores. Segundo Broad (1999), a passagem para a autonomia é um desafio extremamente complexo e exige "apoio financeiro, um lugar para viver, o desejo de sair de casa, uma personalidade resiliente e, por fim, uma rede familiar ou de amigos de apoio" (p. 26). Como conclui o mesmo autor, os custos que a transição acarreta têm sido da responsabilidade das famílias acolhedoras, na ausência de apoios da parte do Estado. Na mesma linha de pensamento, Sinclair, Baker et al. (2005) propõem o prolongamento do apoio financeiro que permita aos jovens permanecerem até ao momento em que se sintam preparados para a mudança, sem que a permanência acarrete desvantagens para os acolhedores.

O desenvolvimento de uma rede de apoio social assente em relações amigáveis que partam do trabalho, da esfera social, recreativa ou até de ajuda profissional, permitem reduzir a solidão e promover a saúde física e emocional (Gilligan, 1998, 2009). Esta rede pode oferecer "bases seguras", que o autor compara aos "campos base" essenciais à sobrevivência dos alpinistas, porque permitem fazer face às adversidades da vida, em tudo semelhantes às bases que os bebés ou crianças pequenas procuram construir junto dos seus pais e a partir das quais partem à exploração do mundo. É necessário tempo e cuidado para desenvolver as relações que sustêm os "campos base", e elas podem encontrar-se "num ex-acolhedor, num parente distante mas simpático, num amigo do trabalho ou de um curso de formação, num antigo vizinho, ou num pai de um colega de desporto" (Gilligan, 1998, p. 88). Este movimento para a autonomia é facilitado quando o sistema, como sucede no Reino Unido, dispõe de serviços especializados com a missão de planificarem e de apoiarem as múltiplas transições que ocorrem nestes anos (leaving care services), da escola para o trabalho, de casa da família de acolhimento para a necessidade premente de ter um alojamento, e a formação, nalguns casos, das suas próprias famílias (Wade, 1999).

Noutros casos, de estadias prolongadas, não há um momento definido em que o acolhimento caduca. A criança acolhida assume um papel em tudo equivalente ao de filho dos acolhedores, prolongando a sua estadia até se emancipar, casar ou ir estudar para uma Universidade, saindo para por vezes regressar, por períodos mais ou menos longos (Schofield \& Beek, 2008). 


\section{Considerações Finais}

Na preparação da colocação, os acolhedores e a criança devem ter a oportunidade de se conhecerem mutuamente, por contacto directo (visitas, passeios, estadias na casa de família pernoitando, inclusivamente), ou indirecto (cartas, telefonemas, mensagens, fotografias, vídeos, entre outros), sendo o primeiro mais adequado e eficaz. Esta aproximação pode passar pela troca de objectos ou pela partilha de desenhos, de histórias, enfim, de todas as estratégias que ajudem a suavizar a fase inicial da integração e que estabeleçam pontes securizantes entre o antes e o depois da colocação. A criança pode levar consigo os seus brinquedos favoritos, certas fotos ou peças de vestuário, que simbolizam uma certa continuidade (Daniel et al., 1999). De preferência, os seus bens devem ser cuidadosamente embalados, e nunca devem ser transportados em sacos de plástico (Romaine et al., 2007).

Os psicólogos ou assistentes sociais das equipas de Acolhimento devem acompanhar de perto a preparação e a fase inicial da estadia, demonstrando a sua disponibilidade e interesse, pois constituem com frequência o único elo entre o passado da criança e o seu conturbado presente (Triseliotis et al., 1995). A sua presença pode ser valiosa no momento da chegada a casa da família em que se inicia o acolhimento.

A programação da colocação varia também consoante o local em que a criança se encontra antes de se iniciar o acolhimento. Se estiver acolhida numa instituição será, em princípio, mais fácil organizar as visitas e as saídas na companhia dos futuros acolhedores. Pelo contrário, se a criança vive com os seus pais e estes se opõem à retirada, a preparação pode ficar irremediavelmente comprometida. Se a criança viveu durante um longo período numa instituição ou se não é feita a preparação, aumentam as dificuldades de integração no acolhimento (Triseliotis et al., 1995).

Quando as circunstâncias do caso permitem preparar a transição, esta deve ser cuidadosamente pensada, planificada e avaliada, no seu decurso. O plano deve ser escrupulosamente seguido, de modo a transmitir uma sensação de ordem e certeza (Daniel et al., 1999). Se possível, deve evitar que a mudança de casa ocorra numa fase do ano que obrigue à mudança de escola, aguardando-se até ao final do ano lectivo (Romaine et al., 2007). Mas esta fase inicial de conhecimento mútuo não se deve prolongar em demasia, sob pena de ser fonte de ansiedade e de angústia para a criança e os acolhedores. Doorbar (1999) salienta o papel das crianças dos acolhedores nesta fase inicial de adaptação, em que a aprendizagem dos papéis, das regras e das relações é mais intensa. Twigg e Swann (2007) efectuaram uma revisão dos estudos desenvolvidos sobre o impacto do acolhimento nos filhos dos acolhedores, uma área de investigação em desenvolvimento.

O modo como ocorre a cessação depende do futuro da criança, porque cada destino representa um ambiente ecológico específico, que condiciona, com as suas características, a preparação da cessação. A criança pode transitar para a adopção, merecendo uma ênfase particular a aproximação e o conhecimento dos pais adoptivos. Se regressa a casa da família, ou se transita para o Acolhimento em Instituição, a abordagem terá de ser necessariamente distinta e ajustada a cada um destes destinos. Sempre que for possível, Barjau (1996, p. 390) sugere a "realização de um ritual de despedida, como uma festa, a troca de presentes, entre outros", devidamente antecedida por conversas antecipatórias do desfecho da estadia, entre os protagonistas do acolhimento.

A transição depende, em segundo lugar, da ligação que existia e da ligação que subsistirá, no futuro, entre os dois ambientes envolvidos, e da forma como estes comunicavam e passam a comunicar entre si. Se foi decidida a reunificação familiar, a integração e a estabilidade da criança joga-se, em grande parte, na oposição ou colaboração que acolhedores e família biológica mantiveram no passado e no grau de concordância que ambas manifestam relativamente à decisão. $\mathrm{O}$ mesmo se pode afirmar relativamente à mudança para a adopção ou para uma nova família de acolhimento.

Um dos factores que mais contribui para o sucesso da mudança para a autonomia é o jovem poder contar com o apoio pessoal e material dos seus antigos acolhedores, que se mantêm assim presentes na sua vida, constituindo referências no seu mapa de identidade, pela importância que tiveram e têm, e pela continuidade e permanência (Brandon, Schofield, \& Trinder, 1998; Romaine et al., 2007; Sinclair, Baker et al., 2005; Triseliotis et al., 2000).

Delgado $(2006,2007,2008)$, defende a utilidade e a valia de se assegurar a manutenção do contacto entre acolhedores e a criança, após a cessação da vida conjunta, se for essa a vontade comum e se motivos de maior gravidade não a desaconselharem., especialmente no caso do acolhimento familiar prolongado. A manutenção do contacto com os acolhedores contribui para que se mobilizem os conhecimentos, os afectos e as experiências que o individuo transporta consigo na mudança, ou o "capital emocional", na expressão de Sinclair et al. (2004, p. 169), facilitando a sua integração no meio a que passa a pertencer.

A transição induzida pela cessação pode ser suavizada com o prolongamento do acompanhamento prestado pelos Serviços Sociais após a saída do Acolhimento Familiar, quer a criança regresse ao seu ambiente familiar ou procure construir a sua autonomia (Triseliotis et al., 1995). No primeiro caso tudo depende, uma vez mais, da idade da criança, do tipo de maltrato sofrido, entre outras variáveis, e da imprevisível interacção que desenvolvem entre si. No pressuposto elementar de que desapareceram as causas que motivaram a aplicação da medida, é útil preparar a criança para o contexto que vai encontrar no regresso a casa, e para as mudanças ocorridas na sua ausência, como um novo bebé na casa, ou um adulto que tenha saído. 
Em síntese, a perspectiva ecológica proporciona um modelo descritivo e compreensivo que permite a identificação das múltiplas variáveis e factores que compõem o Acolhimento Familiar, evidencia os processos que o caracterizam e os potenciais efeitos que pode produzir na integração social e no desenvolvimento das crianças. A leitura ecológica da protecção infantil adverte, no caso específico da colocação familiar, para a importância de, na intervenção, se transmitir aos potenciais acolhedores as informações sobre as características essenciais de cada caso, de assegurar a preparação adequada da criança para o impacto da transição, de se incluir sempre que possível a família biológica na tomada das decisões e de se definir de modo claro os papéis dos diferentes protagonistas no Acolhimento Familiar. No âmbito da cessação, a intervenção deve procurar habilitar os mesmos protagonistas para a mudança, preparando o regresso a casa, a transição para a autonomia (gradual) de vida ou a permanência no seio da família acolhedora, quando não se encontram reunidas as condições para a independência.

\section{Referências}

Alarcão, M. (2000). (Des)equilibrios familiares. Coimbra, Portugal: Quarteto.

Alberto, I. (2004). Maltrato e trauma na infância. Coimbra, Portugal: Almedina.

Almeida, A., André, I., \& Almeida, H. (1999). Famílias e maus tratos às crianças em Portugal. Relatório Final. Lisboa, Portugal: Instituto de Ciências Sociais da Universidade de Lisboa.

Barjau, C. (1996). Acogimiento familiar, un medio de protección infantile. In J. de Paúl \& M. Arruabarrena, Manual de protección infantil (pp. 359-392). Barcelona, España: Masson.

Beek, M. \& Schofield, G. (2004). Promoting security and managing risk: Contact in long-term foster care. In E. Neil \& D. Howe (Eds.), Contact in adoption and permanent Foster Care (pp. 124-143). London: British Association for Adoption and Fostering.

Berridge, D. (1997). Foster Care: A research review. Norwich, UK: The Stationery Office.

Berridge, D. (1999). Work with fostered children and their families. In M. Hill (Ed.), Effective ways of working with children and their families (pp. 240-255). London: Jessica Kingsley.

Brandon, M., Schofield, G., \& Trinder, L. (1998). Social work with children. London: Macmillan.

Broad, B. (1999). Leaving care work - Young people's rights and participation. In A. Wheal (Ed.), Companion to Foster Care (pp. 24-33). Lyme Regis, UK: Russell House.

Bronfenbrenner, U. (1996). A ecologia do desenvolvimento humano: Experimentos naturais e planejados. Porto Alegre, RS: Artes Médicas. (Original work published 1979)

Bronfenbrenner, U. (2005). Making humans beings human. London: Sage.

Bullock, R. (1999). The implications of recent child care research findings for Foster Care. In M. Hill (Ed.), Signpost in fostering. Policy, practice and research issues (pp. 353359). London: British Association for Adoption and Fostering.
Cairns, K. (2002). Attachment, trauma and resilience: Therapeutic caring for children. London: British Association for Adoption and Fostering.

Caride, J., \& Meira, P. (1995). A perspectiva ecológica: Referências para o conhecimento e a praxis educativa. In A. Carvalho (Ed.), Novas metodologias em Educação (pp. 135-170). Porto, Portugal: Porto.

Colton, M., \& Williams, M. (1997). The world of Foster Care: An international sourcebook on Foster Family Care System. Aldershot, UK: Ashgate.

Colton, M., \& Williams, M. (2006). Global perspectives on Foster Family Care. Dorset, UK: Russell House.

Daniel, B., Wassell, S., \& Gilligan, R. (1999). Child development for child care and protection workers. London: Jessica Kingsley.

Delgado, P. (2006). Acolhimento familiar. Conceitos, práticas $e$ (in)definições. Porto, Portugal: Profedições.

Delgado, P. (2007). O acolhimento familiar: Dúvidas, certezas e interrogações. A perspectiva das equipas de acção social local do distrito do Porto. Revista Infância e Juventude, 3, 61-88.

Delgado, P. (2008). Crianças e acolhedores. Histórias de vida em familias. Porto, Portugal: Profedições.

Doorbar, P. (1999). The children of Foster Carers. In A. Wheal (Ed.), The companion to Foster Care. Dorset, UK: Russell House.

Garbarino, J., \& Barry, F. (1999). El contexto comunitário del abuso y descuido del niño. In J. Garbarino \& J. Eckenrode, Porque las famílias abusan de sus hijos (pp. 85-124). Barcelona, España: Granica.

Garbarino, J., \& Eckenrode, J. (1999). El significado del maltrato. In J. Garbarino \& J. Eckenrode, Porque las famílias abusan de sus hijos (pp. 15-44). Barcelona, España: Granica.

García, J., \& Melían, J. (1993). Hacia un nuevo enfoque del Trabajo Social. Madrid, España: Narcea.

Gilligan, R. (1998). Beyond permanence? The importance of resilience in child placement practice and planning. In $\mathrm{M}$. Hill \& M. Shaw (Eds.), Signposts in adoption. Policy, practice and research issues (pp. 80-96). London: British Association for Adoption and Fostering.

Gilligan, R. (2009). Promoting resilience. London: British Association for Adoption and Fostering.

Maluccio, A., Ainsworth, F., \& Thoburn, J. (2000). Child welfare outcome research in the United States, The United Kingdom, and Australia. Washington, DC: Child Welfare League of America Press.

Meira, P. (1999). La perspectiva ecológica en la acción con menores. In J. Ortega (Ed.), Pedagogía Social Especializa$d a$ (pp. 71-79). Barcelona, España: Ariel.

Neil, E., \& Howe, D. (2004). Conclusions: A transactional model for thinking about contact. In E. Neil \& D. Howe (Eds.), Contact in adoption and permanent Foster Care (pp. 224254). London: British Association for Adoption and Fostering.

Orte, C. (1999). Programas de educación familiar: la família como âmbito de acción socioeducativa. In J. Ortega (Ed.), Pedagogia Social Especializada (pp. 79-84). Barcelona, España: Ariel.

Payne, M. (2005). Modern Social Work Theory. London: Macmillan.

Relvas, A. (1996). O ciclo vital da família. Perspectiva sistémica. Porto, Portugal: Afrontamento. 
Romaine, M., Turley, T., \& Tuckey, N. (2007). Preparing children for permanence. London: British Association for Adoption and Fostering.

Schofield, G., \& Beek, M. (2008). Achieving permanence in Foster Care. London: British Association for Adoption and Fostering.

Schofield, G., Beek, M., Sargent, K., \& Thoburn, J. (2000). Growing up in Foster Care. London: British Association for Adoption and Fostering.

Sellick, C. (2006). United Kingdom. In M. Colton \& M. Williams (Eds.), Global perspectives on foster family care (pp. 79-86). Lyme Regis, UK: Russell House.

Sellick, C., \& Thoburn, J. (1997). United Kingdom. In M. Colton \& M. Williams (Eds.), The world of Foster Care (pp. 237248). Aldershot, UK: Arena.

Sellick, C., Thoburn, J., \& Philpot, T. (2004). What works in adoption and Foster Care? Ilford, UK: Barnardo's.

Sinclair, I. (2005). Fostering now. Messages from research. London: Jessica Kingsley.

Sinclair, I., Baker, C., Wilson, K., \& Gibbs, I. (2005). Foster children. Where they go and how they get on. London: Jessica Kingsley.

Sinclair, I., Gibbs, I., \& Wilson, K. (2004). Foster Carers. Why they stay and why they leave. London: Jessica Kingsley.

Sinclair, I., Wilson, K., \& Gibbs, I. (2005). Foster Placements. Why they succeed and why they fail. London: Jessica Kingsley.

Triseliotis, J., Borland, M., \& Hill, M. (2000). Delivering Foster Care. London: British Association for Adoption and Fostering.

Triseliotis, J., Sellick, C., \& Short, R. (1995). Foster Care. Theory and practice. London: Bastford.

Twigg, R., \& Swan, T. (2007). Inside the foster family: What research tell us about the experience of Foster Carers' children. Adoption \& Fostering, 31(4), 49-61.

Wade, J. (1999). Developing leaving care services. In M. Hill (Ed.), Signpost in fostering. Policy, practice and research issues (pp. 46-66). London: British Association for Adoption and Fostering. 